\title{
CONTROLE JUDICIAL DAS POLÍTICAS PÚBLICAS: A DEMAGOGA CONCRETIZAÇÃ̃O DO DIREITO FUNDAMENTAL À SAÚDE
}

PUBLIC POLICIES OF FUNDAMENTAL HEALTH: THE DEMAGOLOGY JUDICIAL CONTROL FOR CONCRETIZATION

Ana Carolina Fontes Figueiredo MENDES ${ }^{1}$

ISSUE DOI: $10.21207 / 1983.4225 .833$

\section{RESUMO}

A Constituição Federal Brasileira garante que a saúde é um direito de todos e dever do Estado de fornecer os serviços e ações a todos, de forma igualitária, através das políticas públicas. Ocorre que o Estado vem fracassando na prestação do direito; desse modo só resta à população ingressar com demandas ao Judiciário na expectativa de ter o direito concretizado. Com a crise sanitária, entretanto, a judicialização está se tornando algo rotineiro e excessivo. Resta analisar se o controle público judicial está sendo eficaz, capaz de garantir o cumprimento constitucional e um mecanismo que possibilita a transformação social e emancipação da população brasileira, através do acesso igualitário na pratica à saúde, ou se o mecanismo está apenas servindo para o uso demagogo dos direitos humanos e gestão de casos individuais. Para tanto foi primordial dialogar com a teoria crítica dos direitos humanos, a qual propõe uma visão emancipadora dos direitos humanos, e prevê que a concretização dos direitos ocorre quando, na pratica, permite acesso aos bens necessários para uma vida digna de ser vivida.

Palavras-chave: Concretização; Controle judicial das políticas públicas; Dignidade humana; Direito fundamental à saúde; Poder Judiciário.

\footnotetext{
${ }^{1}$ Mestranda no Programa de Pós-Graduação em Direito da Universidade Federal de Sergipe-UFS. Bolsista FAPITEC-SE. Mestra em Direitos Humanos, Multiculturalismo e Desenvolvimento - Universidad Pablo de Olavide (2016). Especialista em Direito Público pela Faculdade Maurício de Nassau. Contato: carolfm.adv@hotmail.com http://lattes.cnpq.br/0774624448067425
} 


\begin{abstract}
The Brazilian Federal Constitution guaranteed that health is a right of everyone and the duty of the State to provide services and actions to all, in a equality way, through public policies. It happens that the State has been failing to provide the right; so only alternative to the population is center with demands to the Judiciary in the expectation of having the right materialized. With the sanitary crisis, however, the judicialization is becoming something routine and excessive. It remains to analyze whether judicial public control is being effective, capable of guaranteeing constitutional compliance and a mechanism that enables social transformation and emancipation of the Brazilian population through equal access to health practice, or whether the mechanism is only serving to use human rights in a demagogue way and management of individual cases. For that, it was essential to dialogue with the critical theory of human rights, which proposes an emancipatory vision of human rights, and predicts that the realization of rights occurs when, in practice, it allows access to the goods necessary for a life worth living.
\end{abstract}

Keywords: Concretization; Judicial control of public policies; Human dignity; Fundamental right to health; Judicial power.

\title{
INTRODUÇÃO
}

O direito fundamental social à saúde é garantido constitucionalmente pelo Estado Democrático Brasileiro, através das políticas públicas prestacionais. Como mandamento constitucional exige uma prestação social estatal, entretanto, o fato é que o Brasil vem falhando no cumprimento das prestações sociais, com inúmeros retrocessos na questão do fornecimento dos serviços de saúde.

A priori, o Poder Executivo e o Legislativo são os responsáveis pela formulação e execução das políticas púbicas de saúde, porém, como as inúmeras falhas e omissões, pois, diversas vezes a única solução ao alcance da população é recorrer ao Poder Judiciário, a fim de ter o acesso ao direito à saúde, garantido estatalmente. Essa situação gera uma intensa movimentação no Poder Judiciário para a possibilidade do exercício ao direito à saúde pós-violatório. O fenômeno é chamado de Controle Judicial das Políticas Públicas, e, no início deste remédio, questionou-se muito no país se o Judiciário pode funcionar como controlador das políticas públicas.

A dúvida residia no questionamento se o referido mecanismo faria com que o Poder Judiciário invadisse a competência do Poder Executivo e Legislativo, com isso maculasse a clássica teoria da tripartição dos Poderes concebida por Montesquieu, pedra fundamental para a formação dos Estados-Nações modernos. Após muitos debates jurídicos envolvendo a sociedade brasileira, chegou-se à conclusão que, diante da omissão dos de- 
mais Poderes, o Judiciário - desde que provocado -, poderia agir para assegurar o cumprimento dos mandamentos constitucionais. Ademais, a própria teoria de Montesquieu prevê a sistema de freios e contrafreios, no qual um poder deve controlar o outro para que não haja excessos, desmandos ou injustiças.

Nesse contexto, a população, os Poderes Executivo e Legislativo já aceitaram como legitimo e efetivo o controle judicial das políticas públicas pelo Judiciário. Então esse já não é novidade, contudo, a surpresa reside no fato de que, apesar desse mecanismo já haver sido introduzido na cultura constitucional brasileira há bastante tempo, ainda há inúmeras discussões sobre sua eficácia. Também se questiona o porquê de temas relevantes relacionados ao direito fundamental à saúde só obtiveram respostas judiciais, pelos tribunais superiores, recentemente, apesar de o debate processual já haver se iniciado há bastante tempo. Como foram os casos do tema n॰ 6 do STF e tema n॰ 106 do STJ, referentes ao pedido de fornecimento de medicamento pelo Poder Estatal.

Nesse âmbito, é necessário analisar se o Controle Judicial das Políticas Públicas do Direito Fundamental à Saúde é realmente um mecanismo de promoção do direito à saúde e um instrumento de transformações sociais dos direitos humanos, ou se é somente uma forma de resolver conflitos judiciais individuais? A hipótese é que o mecanismo do controle não está realizando transformação concreta na sociedade, apenas gestiona conflitos individuais para aqueles que conseguem ter acesso à Justiça, e, após vencer a barreira, preencher todos os requisitos de natureza processual.

Com isso, o Estado dá apenas uma parcela mínima do direito humano à saúde para aqueles que, de alguma maneira, protestam diante da não prestação, contudo, esse direito fundamental só é exercido de forma plena e efetiva quando toda a população tem acesso pleno e adequado ao direito à saúde. Situação oposta significa falta de promoção do direito à saúde pelo dito Estado Democrático de Direito.

Na busca por resposta, será essencial a utilização do pensamento metodológico da Teoria Crítica de Herrera Flores, que propõe uma nova visão dos direitos humanos fundamentais, com a perspectiva de focar nas reais necessidades das pessoas, fugindo do uso demagogo dos direitos humano, para alcançar uma dignidade humana emancipadora. Destaca-se, que aqui a dignidade humana é vista como a luta para se alcançar os bens necessários para serem vividos dignamente, que, por consequência, refuta a visão que liga o direito à saúde ao mínimo existencial. 
Nesse âmbito, ressalta-se que a Constituição Federal de 1988 foi promulgada após o fim do período da ditadura militar, neste não havia maior respeito aos direitos fundamentais, então o documento foi um dos passos para a redemocratização, representou grande avanço no que concerne a esses direitos, principalmente quanto aos sociais, que, praticamente, inexistiram durante o turbulento período antidemocrático, no qual o direito à saúde foi inserido no rol dos direitos sociais, consoante seu artigo $6^{\circ}$, também conferiu seção própria, a seção II do título VIII, que se refere à Ordem Social, já o artigo 196 da Constituição Federal, assegurou que este direito é de todos, de acesso igualitário e universal às ações e serviços realizados para a sua promoção, proteção e recuperação. A Constiinda prescreveu como um dever do Estado, devendo ser garantido através de políticas públicas ${ }^{2}$.

Resta ao Estado, portanto, obrigação existencial de promover política pública de acesso igualitário e universal para todas as pessoas, ou seja, o direito à saúde, de forma plena, efetiva e eficaz para acesso préviolatório do direito, sob pena de, se assim não agir, estará descumprindo os objetivos para o qual foi constituído, por isso motivo da própria existência. Com é objetivo estatal, entre outros, a dignidade da pessoa humana, a efetivação dos direitos sociais, a redução da pobreza e da desigualdade, e no momento que a população brasileira padece por falta de acesso ao serviço de saúde pública, o Estado Brasileiro não tem mais razão de ser chamado de Democrático de Direito.

\section{CONSTITUIÇÃO FEDERAL SOB O ENFOQUE DA TEORIA CRITICA DOS DIREITOS HUMANOS}

Antes de adentrar efetivamente nas questões do controle judicial das políticas públicas do direito fundamental à saúde, faz-se necessário adentrar no ponto de interseção entre a ordem constitucional brasileira e o Direito Internacional dos Direitos Humanos, o qual tem por objetivo, em tese, garantir o exercício pleno dos direitos da pessoa humana. Então, ao dirigir as intenções nos direitos da pessoa humana encontra-se com o conteúdo material constitucional. Consequentemente, desenvolver-se-á uma pesquisa com caráter interdisciplinar, que culminará no chamado Direito

\footnotetext{
${ }^{2}$ BRASIL. [(1988) Constituição]. Constituição da República Federativa do Brasil, assinada em 05 de outubro de 1988. Brasília: Senado Federal, 1988.
} 
Constitucional Internacional, com a fusão do Direito Constitucional, Direito Internacional e Direitos Humanos ${ }^{3}$. Alerta-se, que aqui se busca uma nova visão dos direitos humanos, que se desprende da visão demagoga da teoria clássica dos direitos humanos / fundamentais.

A promulgação da Constituição de 1988, após a redemocratização do Brasil, significou um processo que deu abertura à participação popular no processo de elaboração, consequentemente, a mesma foi direcionada para a realização da cidadania, que significou alguma consolidação das liberdades fundamentais e instituições democráticas, nesse compasso abriu espaço para os direitos humanos e reconhecimento dos tratados internacionais, instaurando uma nova do constitucionalismo brasileiro ${ }^{4}$.

A CFB assegura, logo em seu preambulo, que é um Estado Democrático que está " [...] destinado a assegurar o exercício dos direitos sociais e individuais, a liberdade, a segurança, o bem-estar, o desenvolvimento, a igualdade e a justiça como valores supremos de uma sociedade fraterna, pluralista e sem preconceitos, fundada na harmonia social"', nesse sentido, o documento constitucional já determina que está comprometido com os direitos sociais, mais que isso, este é um dos seus objetivos.

É a primeira vez que uma Constituição assinala, especificamente,
objetivos do Estado brasileiro, não todos, que seria despropositado,
mas os fundamentais, e entre eles, uns que valem como base das
prestações positivas que venham a concretizar a democracia eco-
nômica, social e cultural a fim de efetivar na pratica a dignidade da
pessoa humana ${ }^{6}$.

Da analise do preâmbulo e objetivos constitucionais, desprendese que o núcleo está focado na efetivação, na prática da dignidade da pessoa humana, destaca-se que a própria $\mathrm{CF}$ deixou claro que essa efetividade deve sair do mundo normativo para habitar o mundo pratico, sendo essa ressalva importantíssima, porque, mesmo após 30 anos da promulgação do Texto Constitucional, a narrativa dos direitos humanos e fundamentais, no Brasil, o mundo do que é normatizado e a realidade são distante e desconectados.

\footnotetext{
${ }^{3}$ PIOVESAN, Flávia. Direitos humanos e direito constitucional internacional. 15. ed. ISBN 978-8502-61846-6. São Paulo: Saraiva, 2015.

${ }^{4}$ Idem.

${ }^{5}$ BRASIL, Constituição, 1988, op. cit..

${ }^{6}$ SILVA, José Afonso da. Curso de direito constitucional positivo. 18. ed. São Paulo: Revista dos Tribunais, 2000, p. 93.
} 
Essa visão que habita o imaginário jurídico cria dois paralelos, duas realidades, que só favorecem o uso demagogo dos direitos humanos pelo Estado, e a consequente fuga do cumprimento da concretização dos direitos sociais prestacionais, ao passo que cega e acomoda a população que acredita nessa narrativa distorcida de que a legislação prevê um mundo ideal e utópico que não pode ser alcançado.

David Sánchez Rubio, analisa que há uma institucionalização da visão natural e indiscutível da separação da prática e da teoria, e essa é uma das razões que justifica a indolência e passividade no momento da construção do dia a dia dos direitos humanos, que só interessa a quem mais se beneficia com essa narrativa ${ }^{7}$.

Infelizmente, quem mais se beneficia da demagogia é o próprio poder público, que - mesmo diante do mandamento constitucional para promover os direitos sociais - alega que esses não podem ser concretizados já que demandariam altos investimentos, e o Estado brasileiro estaria em crises, não podendo realizar essas demandas. Através do uso dessa falácia, a Proposta de Emenda à Constituição no 55/2016, conhecida como "PEC do Teto dos Gastos Públicos" Emenda Constitucional $n^{\circ} 95 / 2016$, e estabeleceu o limite dos aumento dos gastos públicos à variação da inflação. ${ }^{9}$

Como já mencionado anteriormente, a PEC 55 deu origem à Emenda Constitucional 95, de 16 de dezembro de 2016, e prever que as alterações gerem mais problemas para a já precária prestação do direito à saúde no Brasil, o Instituto Humanitas Unisinos analisa que, na prática, significará um congelamento das despesas primárias, já que as reduzirá ao PIB ou em termos per capita por duas décadas, e que o destinado do PLOA 2019 será de $\mathrm{R} \$ 117,5$ bilhões em recursos para ações e serviços públicos de saúde, consequentemente R $\$ 1,7$ bilhões a menos do destinado ao PLOA $2018 .^{10}$

\footnotetext{
${ }^{7}$ RUBIO, David Sánchez. Encantos e desencantos dos direitos humanos: De Emancipações, libertações e Dominações. Porto Alegre: Livro do Advogado, 2014.

${ }^{8}$ PEC QUE restringe gastos públicos é aprovada e vai a promulgação. 2016. In: Senado Notícias. Disponível em: < https://www12.senado.leg.br/noticias/materias/ 2016/12/13/pec-que-restringe-gastospublicos-e-aprovada-e-vai-a-promulgacao> Acesso em: 22 out. 2018.

${ }_{9}^{9}$ BRASIL. [(1998) Constituição]. Emenda Constitucional 95 de 16 de dezembro de 2016 [Novo Regime Fiscal, PEC do Teto dos Gastos Públicos]. Altera o Ato das Disposições Constitucionais Transitórias, para Instituir o Novo Regime Fiscal, e Dá Outras Providências. Diário Oficial da União de 16/12/2016 (p. 2; col. 2). Brasília, DF, 2016.

${ }^{10}$ PEC TETO dos gastos: uma perda bilionária para o SUS em 2019. 25 Setembro 2018. In: Instituto Humanitas Unisinos. Disponível em: <http://www.ihu.unisinos.br/78-noticias/583072-pec-teto-dosgastos-uma-perda-bilionaria-para-o-sus-em-2019>. Acesso em: janeiro de 2019.
} 
Dos dados apresentados, demonstra-se que a realidade brasileira sobre as políticas públicas não apresenta um cenário otimista, e, se os serviços de saúde pública já são precários, em crise, a previsão é de piora, por isso quem luta para a concretização dos direitos sociais constitucionais e deseja a plena e efetiva realização do direito à saúde para todos, com acesso igualitário e universal, precisa agir para mudar a lógica sistemática que o Estado, dito Democrático Brasileiro, vem desenvolvendo.

O primeiro passo para uma ruptura desse paradigma, que exclui os menos favorecidos do acesso à saúde é a mudança da visão sobre a perspectiva dos direitos humanos, através do fim do uso demagogo do direito fundamental à saúde, e significará uma nova reconstrução na prática do próprio direito à saúde, tal como foi desejado pela constituinte de 1988.

Para tanto, é necessário desconstruir o discurso liberal-hegemônico dos direitos humanos, e uma das principais características a ele inerente é o dito carácter universal, assumida com a Declaração de $1948^{11}$, que reflete na Constituição Brasileira de 1988. Ocorre, que o universalismo contido na declaração, teve como núcleo central o pensamento de superioridade eurocêntrico (WALLERSTEIN, 2007).

\footnotetext{
No caso dos direitos humanos considerados universais - o paradigma do universalismo - comemorados como conquistas do século $\mathrm{XX}$ - as abstrações jurídicas impedem que se vislumbrem saídas mais além do sistema de garantias plasmado na arquitetura jurídica e institucional do marco universalista das Nações Unidas e dos sistemas regionais de proteção, por sua vez replicados em cartas constitucionais e em elencos de direitos fundamentais ${ }^{12}$.
}

É incontestável a hegemonia dos direitos humanos, pois estes também se configuram como uma linguagem da dignidade, porém o discurso convive com a realidade perturbadora de que a maioria da população mundial não é sujeito de direitos humanos. Assim, a partir desse ponto, surge um questionamento: os direitos humanos servem de um instrumento realmente eficaz na luta dos excluídos ou agem de forma contrária, ou seja, será que esse imaginário da normatização dos direitos humanos sempre se

\footnotetext{
${ }^{11}$ ORGANIZAÇÃO DAS NAÇÕES UNIDAS (ONU). Declaração Universal dos Direitos Humanos. Adotada e proclamada pela Assembleia Geral das Nações Unidas (resolução 217 A III) em 10 de dezembro 1948. Paris, 1948.

${ }^{12}$ PRONER Carol. Teoría, crítica dos direitos humanos: das lutas aos direitos sociais. Rio de Janeiro: Lumen Juris, 49-64, 2011, p. 52.
} 
traduz em dignidade humana, ou este paradigma serve apenas para dificultar a luta contra a opressão? ${ }^{13}$

Na mesma linha de raciocínio, Joaquín Herrera Flores ${ }^{14}$ afirma que a idealização sobre os direitos humanos para alcançar a dignidade e exigências normativa de torná-lo mais abstrato e universal, que traz a utopia de que se tem direitos apenas pelo fato de ter nascido, contudo acaba por tornar o direito neutro, num movimento desconecto entre o espaço público e o espaço privado, construindo o ideal de igualdade apenas no plano formal, de modo que o direito não significa o acesso ao bens necessários a uma vida digna, pelo contrário, traduz-se apenas em se ter direitos a ter direitos.

Diante da problemática, é necessária uma análise crítica dos direitos humanos diferente da tradicionalmente já reproduzida, para que se encontre uma metodologia de pensamento para garantir uma prática capaz de garantir o verdadeiro e efetivo acessos aos bens necessários a todas as pessoas, independente das condições sociais ou de vulnerabilidade. Para tanto, a Teoria Crítica dos Direitos Humanos, desenvolvida principalmente por Herrera Flores ${ }^{15}$, apresenta-se como uma solução para uma nova conceituação e novo tratamento aos direitos humanos.

A proposta de Herrera Flores ${ }^{16}$ para sair dessa armadilha é uma visão complexa e com racionalidade de resistência, que inclui a interculturalidade e uma filosofia impura dos direitos (que alia o ordenamento jurídico aos contextos históricos), mediante a qual se fortaleçam os indivíduos, grupos e organizações na hora de construir os planos de ações, que garanta a todos, de modo igualitário, o acesso aos bens materiais e imateriais que fazem a vida digna de ser vivida. A corrente crítica entende os direitos desde uma perspectiva emancipadora, que pretende contribuir para o incremento dos níveis de humanização, concebido como um conjunto de práti-

\footnotetext{
${ }^{13}$ SANTOS, Boaventura de Souza. Direitos humanos, democracia e desenvolvimento. In: SANTOS, Boaventura de Souza; CHAI, Marilena. Direitos humanos, democracia e desenvolvimento. São Paulo: Cortez, 2013; p 41-133.

${ }^{14}$ HERRERA FLORES, Joaquín. O nome do risco. Breve tratado sobre arte e dignidade. Porto Alegre: Movimento; Florianópolis: Bernúncia, 2007.

${ }^{15}$ Idem - Ibidem

${ }^{16}$ HERRERA FLORES, Joaquín. La reinvención de los derechos humanos. Sevilla: Atrapasueños, 2008.
} 
cas sociais, simbólicas, culturais e institucionais que reagem contra os excessos, que impedem os seres humanos de serem reconhecidos como sujei$\operatorname{tos}^{17}$.

Essa proposta deve orientar a construção dos direitos humanos fundamentais sociais, e consequentemente as políticas públicas, especialmente as de promoção dos serviços e ações de acesso à saúde. Contudo, caso o Estado ainda assim se omita em realizar e executar as normas prestacionais do direito à saúde, um dos instrumentos possíveis para reparação do direito pós-violatório é o controle das políticas públicas no Poder Judiciário.

\title{
3 O DIREITO FUNDAMENTAL À SAÚDE
}

A saúde deve ser compreendida no seu sentido amplo, pois é um direito intimamente ligado a vida, e é um componente da qualidade de vida.

\begin{abstract}
O direito à saúde assegura a promoção e o bem-estar físico, mental e social de um indivíduo, impondo ao Estado a oferta de serviços públicos a todos para prevenir ou eliminar doenças ou gravames. $\mathrm{O}$ direito à saúde possui faceta individual e difusa, pois há o direito difuso de todos de viver em um ambiente sadio, sem riscos de epidemias ou outros malefícios à saúde. Por isso, determina a Constituição de 1988 que a saúde é direito de todos e dever do Estado, garantido mediante políticas sociais e econômicas que visem à redução do risco de doença e de outros agravos e ao acesso universal e igualitário às ações e serviços para sua promoção, proteção e recuperação $(\text { art. 195) })^{18}$
\end{abstract}

Dizer que o direito à saúde é um típico direito social "[...] significa dizer que ele se apresenta como direito primário e absoluto, a partir do qual os demais direitos podem ser exercidos, e por esta razão inviolável $[\ldots]^{\prime \prime 19}$

Outrossim, somente com a concretização do direito à saúde haverá concretização do direito à igualdade, previsto no art. $5^{\circ}$ da $\mathrm{CF} / 88$, já que o direito à saúde só pode ser plenamente efetivo quando todos o têm.

\footnotetext{
${ }^{17}$ RUBIO, David Sánchez. Repensar los derechos humanos. De la anestesia a la sinestesia. Sevilha: Editorial Mas, 2007.

${ }^{18}$ RAMOS, André de Carvalho. Curso de direitos humanos. 5. ed. São Paulo: Saraiva, 2018, p. 815.

${ }^{19}$ LEAL, Rogério Gesta. A efetivação do direito à saúde por uma jurisdição-serafim: limites e possibilidades. A \& C revista de Direito Administrativo e Constitucional, Belo Horizonte, ano 6, n. 25, p.2540, jul/set. 2006, p. 26; ISSN 1516-3210.
} 
Nesse sentido, Oscar Vihena Vieira ${ }^{20}$ explica que é justamente para alcançar o direito à igualdade que o direito a saúde é universal; com isso, mitigase a ideia da igualdade entendida apenas pela acepção da imparcialidade por parte do Estado, para alcançar o sentido de igualdade redistributiva, tão importante em um país como imensas desigualdades, a fim de superar as injustiças sociais.

Assim, considerando que o reconhecimento do direito à saúde é o reconhecimento do direito à igualdade, pode-se abstrair dessa relação também a metáfora do direito à fraternidade. Partindo desse pressuposto, uma sociedade só tem o direito fundamental à saúde garantido quando todas as pessoas podem usufruí-la de forma igualitária e irrestrita.

Acrescenta-se que, justamente para alcançar a igualdade, a Carta Constitucional de 1988 garantiu o acesso universal de todos, independentemente de mérito ou necessidade, isto demora que todos têm direito à prestação do serviço da saúde ${ }^{21}$. Enfatiza-se que a universalidade abrange tanto o direito à cobertura quanto ao atendimento, como estabelece o art. 194, inc. I da Constituição Federal Brasileira, independente da classe social e de qualquer contribuição. ${ }^{22}$

Ressalta-se que o sentido dado ao universal e à igualdade não pode ser aquele que se traduz em direito a ter direitos, deve sim ser traduzido em igualdade de fato, não apenas formal, e universalidade na prática, e não serem utilizados de forma demagoga para gerar mais injustiças. "Considerando-se que o reconhecimento do direito à saúde é também o do direito à igualdade, pode-se subtrair desta relação também a metáfora do direito à fraternidade" 23

Do direito à saúde também se subtrai o da dignidade da pessoa humana, direito de suma importância, já que é um dos fundamentos da República Federativa do Brasil, estabelecidos pelo art. $1^{\circ}$ da $\mathrm{CF} / 88$. Com isso, para que haja vida digna, é necessário que todos vivam bem e, por conseguinte, com saúde, em sentido amplo. "Partindo deste pressuposto, uma

\footnotetext{
${ }^{20}$ VIEIRA, Oscar Vilhena. Direitos fundamentais: uma leitura da jurisprudência do STF. 2. ed. São Paulo: Malheiros, 2017.

${ }^{21}$ VIEIRA, op. cit., 2017.

${ }^{22}$ BRASIL, op. cit. [Constituição (1988)].

${ }^{23}$ SILVA, Luciana Aboim Machado Gonçalves da; MENDES, Ana Carolina Fontes Figueiredo. Controle judicial das políticas públicas e o direito fundamental à saúde no sistema jurídico brasileiro. In: STURZA, Ana Elizabeth Cavalcanti; MARTINI, Sandra Regina (org.). A transdisciplinaridade e o direito: direito à saúde na sociedade em rede. Os movimentos entre os saberes, v. 10. Porto Alegre: Evangraf / Exclamação, 2018, p. 82.
} 
sociedade só tem o direito fundamental à saúde garantido quando todas as pessoas podem usufruí-lo de forma igualitária e irrestrita" 24 .

Aliás, é através da proteção do direito à saúde que se protege o bem maior assegurado pelo ordenamento jurídico brasileiro: o direito à vida, direito este, de acordo com o art. $5^{\circ}$ da Constituição Federal, inviolável. Somente há garantia de uma vida digna, quando há bem-estar e vida saudável. Assim é o entendimento STF, como se depreende da Ementa do RE-AgR 271286 RS, de relatoria do ministro Celso de Melo:

PACIENTE COM HIV/AIDS - PESSOA DESTITUÍDA DE RECURSOS FINANCEIROS - DIREITO À VIDA E À SAÚDE FORNECIMENTO GRATUITO DE MEDICAMENTOS - DEVER CONSTITUCIONAL DO PODER PÚBLICO (CF, ARTS. 5, CAPUT, E 196) - PRECEDENTES (STF) - RECURSO DE AGRAVO IMPROVIDO. O DIREITO À SAÚDE REPRESENTA CONSEQÜÊNCIA CONSTITUCIONAL INDISSOCIÁVEL DO DIREITO À VIDA ${ }^{25}$.

Consequentemente, o direito à saúde, ao passo que consagra o direito à dignidade humana, fundamento da República, e o direito à vida, representa a decorrência constitucional indissolúvel do direito à vida. Ressalta-se que o direito à saúde deve ser concretizado na pratica, porque só normatização não significa a promoção da dignidade humana. "Para que haja vida digna, é necessário que todos vivam bem e, por conseguinte, com saúde, em sentido amplo" ${ }^{26}$. Lembra-se que a "[...] dignidad es un fin material. Un objetivo que se concreta en dicho acceso igualitario y generalizado a los bienes que hacen que la vida sea "digna' de ser vivida"27 28 .

Nesse sentido, o direito à saúde não pode ser confundido com direito à subsistência, pois é conceito intimamente ligado à noção de dignidade humana, e esta só é alcançada quando há efetivo acesso aos bens

\footnotetext{
${ }^{24}$ SILVA, Luciana Aboim Machado Gonçalves da; MENDES, Ana Carolina Fontes Figueiredo. Controle judicial das políticas públicas e o direito fundamental à saúde no sistema jurídico brasileiro. In: STURZA, Ana Elizabeth Cavalcanti; MARTINI, Sandra Regina (org.). A transdisciplinaridade e o direito: direito à saúde na sociedade em rede. Os movimentos entre os saberes, v. 10. Porto Alegre: Evangraf / Exclamação, 2018, p. 82.

${ }^{25}$ BRASIL. Supremo Tribunal Federal. RE-AgR 271286 RS. Paciente com HIV/AIDS. Pessoa destituída de recursos financeiros. Direito à vida e à saúde. Fornecimento gratuito de medicamentos. Dever constitucional do poder público (Cf. arts. $5^{\circ}$ caput e 196). Relator. Celso de Mello. Órgão Julgador: Segunda Turma. Julgamento: 12 de setembro de 2000. Publicação: Diário de Justiça de 24-11-2000 PP-00101 Ement Vol-02013-07 pp-01409. Brasília, DF, 2000.

${ }^{26}$ SILVA; MENDES, op. cit., 2018, p. 26.

${ }^{27}$ HERRERA FLORES, op. cit., 2008, p. 26

28 "Dignidade é um fim material. Um objetivo que se concretiza no acesso igualitário e generalizado dos bens que fazem com que a vida seja "digna" de ser vivida". (Tradução nossa)
} 
essencial a uma vida digna, devendo refletir a realização do ser humano. Portanto aqui não se adota que o entendimento de que o direito à saúde é a garantia para um "mínimo existencial" 29 , pois isso seria recair no uso demagogo dos direitos humanos.

A construção teórica que relaciona o direito à saúde à teoria do mínimo existencial é um caminho que requer especial atenção para não gerar a impressão de que basta dar um mínimo necessário à sobrevivência da pessoa, o que poderia retomar a ideia, já ultrapassada, de direito à saúde como sendo a ausência de enfermidades, sendo que, como já dito, compreende uma ideia muito mais ampla.

Esse direito essencial ao ser humano deve proporcionar uma vida saudável e digna através do gozo dos bens necessários em sua ampla acepção. ${ }^{30}$

Ocorre que, como o direito à saúde é um direito social que exige prestações positivas do Estado para ser garantido, a forma pela qual cada país elege as políticas públicas de direito à saúde será determinante. Assim, a efetivação do direito à saúde somente ocorre propriamente quando o Estado age positivamente de modo a concretizá-lo.

Entrementes, apesar de haver motivos para celebrar que o ordenamento brasileiro, através da hodierna normatização constitucional, enalteceu a promoção do direito à saúde, constata-se que a realidade social de exercício deste direito não é digna de qualquer celebração, uma vez que o cenário da saúde pública no país é de crise. ${ }^{31}$

Diante da crise na saúde, questiona-se a atuação estatal, já que "[...] para o exercício do direito à saúde pela população, impedem [sic] prestações positivas por parte do Estado para sua devida concretização, cabendo eleger políticas públicas que ensejam a máxima efetividade deste direito social". ${ }^{32}$ Conclui-se que a atuação do Estado Democrático de Direito será determinante para a concretização e eficácia do direito fundamental à saúde, e, caso a democracia não funcione de forma a promover a

\footnotetext{
${ }^{29}$ Ordacgy, por exemplo, adoto esse pensamento que estabelece que direito à saúde consagração da "teoria do mínimo existencial de dignidade humana", sendo este definido pela seguinte explicação: "há um ponto do qual nem mesmo os mendigos, os indigentes, os inválidos e toda sorte de desfavorecidos podem ser afastados, de modo que fazem jus, ao menos, aos direitos considerados mais básicos ao ser humano, como o direito à vida, à saúde e à liberdade (ORDACGY, André da Silva. A tutela de saúde como um direito fundamental do cidadão. 24.05.2006. Disponível em: < http://www.ceap-rs.org.br/wpcontent/uploads/2014/02/Direito-Humano-a-saude-oublica.pdf >. Acesso em: 23 mar. 2018.)

${ }^{30}$ SILVA; MENDES, op. cit., 2018, p. 83.

${ }^{31}$ SILVA; MENDES, op. cit., 2018, p. 81.

${ }^{32}$ Idem-Ibidem, p. 83.
} 
justiça social, é necessário buscar instrumentos do direito para a população assegurar o cumprimento do direito fundamental.

\section{POLÍTICAS PÚBLICAS E A JUDICIALIZAÇÃO DO DIREITO À SAÚDE}

O direito à saúde como um direito fundamental social demanda do Estado prestações para garantir a efetividade, sob pena de ineficácia, assim pressupõe-se a prestação estatal, será por meio desta se alcançará a justiça social, de tal modo o Estado é obrigado a intervir ativamente para produzir e concretizar a organização dos serviços públicos essenciais à sociedade, através de serviços essenciais para a garantir uma vida digna de ser vivida. O direito a saúde somente será pleno e eficaz quando o Estado for capaz de fornecer a prestação deste serviço de maneira apropriada a todos, não basta o mandamento normatizando a existência no plano formal do direito.

Não há qualquer dúvida de que as leis constitucionais brasileiras tenham eficácia normativa no que se refere ao direito à saúde, sendo superior a qualquer outro texto normativo existente no país. Nesse caminho, o direito à saúde, como explica Rogério Gesta Leal (2006), não pode ser interpretado como uma norma de eficácia limitada.

Apesar de não limitada, a implementação do direito à saúde ocorre por meio de políticas públicas, explica-se que estas são tanto um instrumento estatal que serve para garantir este direito fundamental, através das leis e ações, como também um instrumento da população para cobrar as promessas feitos pelo poder público. As políticas públicas são “[...] o principal mecanismo de ação estatal com vistas à realização dos direitos sociais, econômicos e culturais, significa tomá-las como um veículo privilegiado de realizações desses direitos, tendo em vista serem eles os fins do Estado Constitucional." 33

Entende-se por políticas públicas o resultado da dinâmica do jogo de forças que se estabelece no âmbito das relações de poder, relações essas constituídas pelos grupos econômicos, políticos, classes sociais e demais organizações da sociedade civil. Tais relações determinam um conjunto de ações atribuídas à instituição estatal, que provocam o direcionamento e/ou o redirecionamento dos rumos

\footnotetext{
${ }^{33}$ BREUS, Thiago Lima. Políticas públicas no estado constitucional. Belo Horizonte: Fórum, 2007, p. 204.
} 
das ações de intervenção administrativa do Estado na realidade social e/ou investimentos. ${ }^{34}$

Outrossim, as políticas públicas devem ser entendidas como o instrumento para o Estado viabilizar o alcance da dignidade de todos, sendo o povo o receptor das políticas. Nesse sentido, alega-se que as políticas públicas têm como proposta a resolução de problemas políticos que se originam de incômodos sociais, por meio da busca de uma melhor participação do cidadão no cenário social, para, assim, conceder condições mais dignas e igualitárias a todos, fato que acontece por meio de uma atuação estatal, quer dizer por intermédio da implementação de Políticas Públicas que sejam específicas e eficazes. ${ }^{35}$

É fundamental a definição dos problemas a serem enfrentados, do ponto de vista estratégico, pois a forma como o problema vai ser definido pode determinar o sucesso de uma questão ${ }^{36}$. Assim, as políticas públicas devem ser orientadas e elegidas de modo a visar sempre atingir o direito fundamental à saúde, sem deixar de lado a boa estratégia e boa técnica para que elas sejam além de justas e eficazes.

Então, para a busca da justiça social, a Constituição Federal, no art. 196 estabeleceu que é dever do Estado garantir, através de políticas públicas sociais e econômicas, o acesso universal e igualitário a todos, a promoção, proteção e recuperação da saúde, e definiu no art. 194 que a principal política do direito à saúde é abarcada pelo de seguridade social, sendo parte integrante deste o Sistema Único de Saúde. ${ }^{37}$

Com isso, a Constituição Federal do Brasil por si só basta para garantir esse direito aos cidadãos. Contrapondo todos os argumentos favoráveis à plena efetivação do direito social à saúde surgem aqueles que tentam barrá-los, argumentando que é difícil efetivá-los e, assim, fazem uso da reserva do possível ${ }^{38}$, para, de forma demagoga, esquivar o poder público estatal de cumprir o objetivo constitucional da implementação do direito à saúde.

\footnotetext{
${ }^{34}$ BONETI, Lindomar Wessler. Políticas públicas por dentro. Ijui (RS): Unijui, 2007, p. 74.

${ }^{35}$ BUCCI, Maria Paula Dallari. "Notas para uma metodologia jurídica de análise de políticas públicas". In: FORTINI, Cristina; ESTEVES, Júlio C. S; DIAS, Maria Teresa F. (Org.) Políticas públicas possibilidades e limites. Belo Horizonte: Fórum. 2008.

${ }^{36}$ CAPELLA, Ana Claudia N. Perspectivas teóricas sobre o Processo de Formulação de Políticas Públicas. In: HOCHMAN, Gilberto; ARRETCHE, Marta; MARQUES, Eduardo (Org). Políticas públicas no Brasil. Rio de Janeiro: Fiocruz, 2007.

${ }^{37}$ BRASIL. [Constituição (1988)], op. cit., 1988.

${ }^{38}$ Nesse sentido, "[...] a expressão reserva do possível procura identificar o fenômeno econômico da limitação dos recursos disponíveis diante das necessidades quase sempre infinitas a serem por elas
} 
Ocorre, que a reserva do possível é uma criação do direito alemão, proveniente de uma realidade jurídica e social divergente da brasileira, e fazer uso do direito alienígena pode resultar na má compreensão ou impropriedade da transposição diante da do contexto diverso; dessa maneira, decisões que fazem referência ao instituto, ou à própria doutrina, ao acolher a reserva do possível, de forma cômoda, acaba por criar obstáculos a implementação dos direitos sociais. ${ }^{39}$ A reserva do possível jamais pode ter como consequência a ineficácia dos direitos fundamentais. A cláusula trata de "[...] objeção à efetividade social dos direitos sociais a prestações materiais, mas cuja interpretação e vigência devem conformar-se, entre outros, aos princípios da proporcionalidade e razoabilidade, unidade e supremacia da Constituição."40

Ademais, o instituto alemão é uma falácia do neoliberalismo contemporâneo, trasvestido de uma racionalidade enganosa, para barrar a concretização fática dos direitos sociais prestacionais, através da manipulação sobre a verdade dos custos de implementação dos direitos fundamentais. ${ }^{41}$ Então, ante a brutal realidade brasileira, na qual a população carece de um padrão mínimo de prestações sociais para sobreviver, com cada vez mais excluídos, e, em face da crise na saúde, aplicar a reserva do possível é violentar ainda mais a população.

Infelizmente a realidade social brasileira é injusta, aliás o cenário é de retrocesso na concepção de saúde pública, que teve início no final do século XX, um dos causadores foi o "[...] relativo fracasso das políticas estatais de prevenção, que não conseguiram superar os limites impostos pela exclusão social [...]." ${ }^{42}$ Mais uma vez, a ideologia neoliberal, dominante no país, foi responsável pela diminuição da atuação do Estado na

supridas" (BARCELLOS, 2008, p.261). Essa teoria surgiu com o intuito de "[...] exprimir a ideia de que os direitos sociais e prestações materiais estariam sob reserva das capacidades financeiras do Estado, se e na medida em que consistem em direitos a prestações financeiras pelos cofres públicos" (FIGUEIREDO, 2007, p.131-132).

${ }^{39}$ PIMENTA, José Marcelo Barreto. Reserva do possivel e a força dirigente dos direitos fundamentais sociais. Curitiba: Juruá Editora, 2016.

${ }^{40}$ FIGUEIREDO, Mariana Filchtiner. Direito fundamental à saúde: parâmetro para sua efetividade. Porto Alegre: Livraria do Advogado Editora, 2007, p. 133.

${ }^{41}$ BARRETO, Vicente de Paulo. Reflexões sobre direitos sociais. In: SARLET, Ingo Wolfgang (Org.). Direitos fundamentais sociais. Estudos de direitos constitucional, internacional e comparado. Rio de Janeiro: Renovar, 2003.

${ }^{42}$ DALLARI, Dalmo de Abreu. Elementos de teoria geral do Estado. 24. ed. São Paulo: Saraiva, 2003, p. 43. 
saúde pública, criando, desta feita, a ideia de que os comportamentos individuais é que eram determinantes na obtenção da saúde. ${ }^{43}$

Como consequência das omissões estatais, inúmeras ações surgiram perante o Poder Judiciário questionando a falta de concretização e de prestação do direito fundamental à saúde, com o intuito da realização do controle judicial das políticas públicas, e corrigido o déficit na implementação deste direito fundamental.

O controle das políticas públicas pelo Poder Judiciário porque os poderes Executivo e Legislativo não formularam elou executaram políticas públicas capazes de concretizar os direitos fundamentais, especialmente $o$ direito à saúde. É verdade que, a priori, incumbe aos poderes Legislativo e Executivo formular e executar as políticas públicas num Estado Constitucional de Direito, mas eles não poderão se valer dessa prerrogativa para elaborá-las arbitrariamente, esquecendo dos preceitos constitucionais e utilizando aquelas para melhor lhes favorecer, cabendo ao Poder Judiciário agir nas falhas. A própria "Constitution aims to remove some questions from the domain of political decision-making" 4445 para garantir a proteção aos direitos fundamentais.

Nesse contexto, demandas judiciais surgem para pleitear que o Estado efetue as prestações positivas. "Desse modo, os tribunais, sempre que uma política perpetrar uma violação aos direitos fundamentais, podem ser provocados para atuar de modo a viabilizar a preservação destes."46. "The conventional move to solve the problem of courts in democratic theory is to celebrate the role of judicial review in democracy as a check on majority power. Judicial review in this view can facilitate the democratic process by clearing out obstacles to its advancement. ${ }^{47} 48$ ".

Na medida em que o Poder Judiciário age para suprir a carência da população em ter seus direitos efetuados, ele assume papel de maior importância no Estado Democrático de Direito, passando a exercer papel mais atuante e a ter uma função política de grande relevância dentro do

\footnotetext{
${ }^{43}$ DALLARI, op. cit., 2003, p. 43.

44 "A Constituição visa remover algumas questões do domínio do tomador de decisões políticas"

${ }^{45}$ FALLON JR., Richard H. The dynamic constitution. Cambridge: Cambridge University Press, 2004, p. 15.

${ }^{46}$ DIAS, Jean Carlos. O Controle judicial das políticas públicas. São Paulo: Método, 2007, p. 126.

${ }^{47} \mathrm{O}$ movimento convencional para resolver o problema dos tribunais na teoria democrática é celebrar o papel da revisão judicial na democracia como um controle do poder da maioria. A revisão judicial nessa visão pode facilitar o processo democrático ao eliminar os obstáculos ao seu avanço.

${ }^{48}$ GINSBURG, Tom. Judicial review in demorcracies. Cambridge: Cambridge University Press, 2003, p. 21.
} 
país ${ }^{49}$. O Judiciário assume um papel ativo e de extrema importância, atuando nas ações administrativas para suprimir as omissões, ampliando o sentido da intepretação constitucional.

A despeito do debate acerca da judicialização do direito à saúde, argumentava-se que haveria uma intromissão dos Poderes, rompendo o princípio da separação destes e a consequente politização do Judiciário, o qual não seria o legitimado pela população para escolher as políticas públicas, por seus membros não terem sidos eleitos. ${ }^{50}$ Essa discussão vem sendo superada, em vista de que o papel do Poder Judiciário deve ser o de resguardar o processo democrático e promover os valores constitucionais, superando o vácuo criado pelos demais Poderes ${ }^{51}$. Ademais, o controle judicial constitui-se como um mecanismo seguro para os próprios elaboradores da Constituição, inclusive contra o uso das políticas públicas como barganhas para os políticos. ${ }^{52}$

Nesse âmbito, nos últimos dois séculos o papel supremo das cortes/tribunal judicial passou a ser justificado por duas correntes doutrinárias. A mais tradicional baseia-se na soberania popular e na separação dos Poderes, e entende a Constituição Federal como expressão maior do povo, a qual deve prevalecer sobre leis, já que é manifestação da maioria parlamentar. Já a segunda reconhece o papel do intérprete na interpretação das normas, o qual deve superar o papel mais formal e mecanicista para enfrentar a realidade, o papel do controle de constitucionalidade deve fundamentar-se na preservação das condições essenciais de funcionamento do

\footnotetext{
${ }^{49} \mathrm{O}$ fato é que o Judiciário se converte, cada vez mais, numa espécie de alvo privilegiado da matriz organizacional do Estado para a locação e processamento das reivindicações veiculadas pelos movimentos sociais. Evita, assim, que demandas básicas e de grande repercussão social conduzam à ruptura da ordem institucional (RIBEIRO apud DIAS, 2007, p.126).

${ }^{50}$ BARROSO, Luís Roberto. Curso de direito constitucional contemporâneo: Os conceitos fundamentais e a construção do novo modelo. $7^{\circ}$ ed. São Paulo: Saraiva Educação, 2018.

${ }^{51}$ Nesse sentido expos o Ministro Celso de Mello, nos autos da ADPF 4: "É certo que não se inclui, ordinariamente, no âmbito das funções institucionais do Poder Judiciário - e nas desta Suprema Corte em especial - a atribuição de formular e implementar políticas públicas [...], pois nesse domínio, o encargo reside, primeiramente, nos Poderes Legislativo e Executivo. Tal incumbência, no entanto, embora em bases excepcionais, poderá atribuir-se ao Poder Judiciário, se e quando os órgãos estatais competentes, por descumprirem os encargos político-jurídicos que sobre eles incidem, vierem a comprometer, com tal comportamento, a eficácia e integridade de direitos individuais e/ou coletivos impregnados de estatura constitucional, ainda que derivados de cláusulas revestidas de conteúdo programático (BRASIL, 2013; suprimimos).

${ }^{52}$ GINSBURG, op. cit., 2003
} 
Estado Democrático. Nesse contexto, o controle das políticas públicas também é demarcado no limite adequado entre as matérias constitucionais e a matéria submetida pelo processo majoritário ${ }^{53}$.

É importante destacar também que, ao realizar o controle judicial das políticas públicas do direito fundamental à saúde, as "courts participate in 'dialogues' with other forces, dialogues that create a shared understanding of what the constitution says over time ${ }^{54,55}$. Assevera-se então que este mecanismo não permite a revisão das políticas somente pelo Poder Judiciário, mas também permite participação ativa do povo.

Os argumentos que criavam entreves judicialização das políticas públicas do direitos são falácias, introduzidos pelo pensamento liberal hegemônico, e resume-se em três pontos: os custos de implementação dos direitos sociais, falta de legitimidade democrática do Poder Judiciário e a falta de conhecimento técnico que teriam os juízes no momento de proferir suas decisões. ${ }^{56}$ Argumentos, que em tese, já foram superados, já que no Brasil é pacifico o entendimento sobre a possibilidade do controle judicial das políticas públicas de direito à saúde, resta saber se este instrumento judicial está operando efetivamente para concretizar, de forma plena e para todos, o direito fundamental à saúde.

\section{A PROBLEMÁTICA CONCRETIZAÇÃO DO DIREITO À SAÚDE: OS CASOS DOS TRIBUNAIS SUPERIOR BRASILEIROS}

Nos últimos 30 anos, a versão neoliberal dos direitos humanos repôs a doutrina liberal "[...] com maior extremismo e com maior hostilidade em relação a promoção dos direitos sociais e econômicos por parte do Estado." $57 \mathrm{O}$ fenômeno do pensamento liberal foi impulsionado pelo processo de globalização que trouxe inúmeras consequências para a prestação

\footnotetext{
${ }^{53}$ BARROSO, op. cit., 2018

${ }^{54}$ Os tribunais participam de 'diálogos' com outras forças, diálogos que criam um entendimento compartilhado do que a constituição diz ao longo do tempo.

${ }^{55}$ GINSBURG, op. cit., 2003, p. 67.

${ }^{56}$ PISARELLO, Gerard. Los derechos sociales y sus garantías. Madrid: Editorial Trotta, 2007.

${ }^{57}$ SANTOS, op. cit., 2013, p. 67
} 
estatal dos direitos sociais, ao passo que enfraqueceu o Estado, por desprezar o poder prestacional estatal, mas que, ao mesmo tempo multiplica a recorrência ao judiciário. ${ }^{58}$

Nesse sentido, há a crescente judicialização do direito fundamental à saúde, como sendo um meio de empoderamento e mecanismo do cidadão, diante da falta de acesso aos serviços públicos de saúde, pleitear diretamente ao Poder Público a possibilidade ter acesso ao direito. Contudo, é preciso ter cuidado com esse pensamento, aparentemente emancipador, sobre a judicialização, para não cair numa armadilha do uso demagogo dos direitos humanos.

Ademais, o cidadão só judicializa o direito à saúde porque, em princípio, houve uma omissão estatal, caso esse direito fosse concretizado tal qual está normatizado constitucionalmente não haveria necessidade de demandar ao Judiciário. David Sánchez Rubio ${ }^{59}$,alerta que o próprio Estado institucionaliza a separação entre o que se diz na lei e o que se ocorre na pratica, para que a população aceite isso como natural e indiscutível, por sua vez essa visão reforça a hegemonia entre separação do normatizado e o da pratica em matéria de direitos humanos. ${ }^{60}$

De tal modo, o imaginário jurídico relaciona-se apenas aos elementos do reconhecimento normativo, eficácia e efetividade com os direitos humanos, conectando estes à existência de tribunais de direitos nos quais podem ser feitas denúncias de situações de violações, para o exercício pleno dos direitos, ocorre na violação à dignidade do trabalhador face à prática do trabalho escravo moderno; nesse compasso esquece-se da dimensão pré-violatória dos direitos humanos, o que delega um protagonismo exacerbado aos funcionários judiciais. ${ }^{61}$

O controle das políticas públicas por órgãos judicias não deve ser negado à população, pelo contrário, negar acesso ao Judiciário, além de ir de encontro a um direito humano, é permitir que o Estado descumpra seus objetivos constitucionais e a população padeça sem qualquer remédio democrático. $\mathrm{O}$ problema está justamente no paradoxo que esse imaginário cria, porque, ao passo que se judicializa excessivamente a saúde, reforça o ativismo judicial, e os demais poderes acabam por abstrair-se do fornecimento do serviço, e a sociedade encara isso como algo natural. "Por estas

\footnotetext{
${ }^{58}$ GARAPON, Antoine. O juiz e a democracia. O guardião de promessas. 2. ed. Rio de Janeiro: Revan, 1999.

${ }^{59}$ RUBIO, op. cit., 2014.

${ }^{60}$ RUBIO, op. cit., 2014.

${ }^{61}$ Idem - Ibidem
} 
razões - diferentes de país para país, mas convergentes no sentido geraltemos mesmo vindo a assistir, em alguns países, a um deslocamento da legitimidade do Estado: do poder executivo e do poder legislativo para o poder judiciário" 62 .

Este movimento ao Judiciário pode gerar problemas justamente para a concretização do direito à saúde, "[...] grande questão não é o 'quanto de judicialização', mas 'como as questões judicializadas' devem ser decididas [...]", ${ }^{63}$ por isso há uma intensa denúncia do protagonismo judicial, pelo perigo que pode acertar para a representação política, já que uma "[...] ofensa à Constituição por parte do Poder Judiciário sempre é mais grave do que qualquer outra desferida por qualquer dos outros Poderes, porque é ao Judiciário que cabe sua guarda. Quem nos salvará se não há mais salvadores? Ou pior: quem nos salvará dos salvadores? ${ }^{64}$

Boaventura de Sousa Santos analisa mais um risco, o processo de globalização introduziu a lógica neoliberal judiciário, o que exige este ser célere e dotado de previsibilidade nas decisões para primar o princípio da segurança jurídica. ${ }^{65}$ Então, com essa premissa, e com inúmeros processos pleiteando o direito a saúde, pode-se imaginar que muitos casos serão solucionados rapidamente em detrimento da efetiva justiça social, com isso ocorrerá "julgamento sem base concreta, passando o Judiciário a julgar teses ao invés de casos (o que, inclusive, fere toda a tradição do common law)?"66.

Diante do cenário, resta analisar como ocorre o controle das políticas públicas relativas ao direito fundamental à saúde nos tribunais mais relevantes em matéria de proteção à Constituição Federal, no Supremo Tribunal Federal e no Superior Tribunal de Justiça; para tanto serão analisados os casos que deram origem ao tema $n^{\circ} 6$ do STF e tema n॰ 106 do STJ, referentes ao pedido de fornecimento de medicamento pelo Poder Estatal.

\footnotetext{
${ }^{62}$ SANTOS, Boaventura de Souza (org). A globalização e as ciências sociais. São Paulo: Cortez, 2005.

${ }^{63}$ STRECK, Lenio Luiz. O ativismo judicial existe ou é imaginação de alguns? Senso Incomum Conjur. 13 de jun 2013. Disponível em: < https://www.conjur.com.br/2013-jun-13/senso-incomum-ativismoexiste-ou-imaginacao-alguns > Acesso em: 22 out. 2018.

${ }^{64}$ Idem - Ibidem

${ }^{65}$ SANTOS, op. cit., 2005.

${ }^{66}$ STRECK, op. cit., 2013
} 
No caso do Supremo Tribunal Federal ${ }^{6768}$ o tema no 6 enuncia que é: "[...] dever do Estado de fornecer medicamento de alto custo a portador de doença grave que não possui condições financeiras para compralo". O leading case foi o RE 566471, o relator o Ministro Marcos Aúrelio (STF, 2018). Aqui se discute se o portador de doença rara tem direito ao fornecimento pelo Estado de medicamentos de uso costumeiro e de extrema necessidade para a promoção da saúde ou minimizar os efeitos da doença, ante questões orçamentárias estatais. Esta questão ainda não foi pacificada, existindo muitas demandas judiciais para obter este direito, por isso o RE foi considerado com repercussão geral, e está pendente de decisão do STF.

Já no Superior Tribunal de Justiça ${ }^{6970}$ foi realizado o julgamento do tema n॰ 106 o qual, através do REsp 1657156, questionava o fornecimento, pelo poder público de medicamentos não incluídos em lista do Sistema Único de Saúde (SUS). A Primeira Seção do Superior Tribunal de Justiça (STJ) julgou o recuso repetitivo relatado pelo ministro Benedito Gonçalves, para fixar os requisitos do fornecimento de medicamento, fora da lista do Sistema Único de Saúde (SUS), pelo Poder Judiciário. ${ }^{71}$

\footnotetext{
${ }^{67}$ EMENTA Agravo regimental no recurso extraordinário com agravo. Direito Constitucional. Direito à saúde. Fornecimento de medicamento de alto custo. Repercussão geral reconhecida. Manutenção do julgado em que se determinou o retorno dos autos à origem. Precedentes. (ARE 832985 AgR, Relator(a): Min. DIAS TOFFOLI, Segunda Turma, julgado em 04/08/2015, PROCESSO ELETRÔNICO DJe-174 DIVULG 03-09-2015 PUBLIC 04-09-2015)

${ }^{68}$ Ementa: RECURSO EXTRAORDINÁRIO. FORNECIMENTO DE MEDICAMENTO E MANUTENÇÃO EM ESTOQUE. DOENÇA DE GAUCHER. QUESTÃO DIVERSA DE TEMA COM REPERCUSSÃO GERAL RECONHECIDA. SOBRESTAMENTO. RECONSIDERAÇÃO. PREQUESTIONAMENTO. OCORRÊNCIA. AUSÊNCIA DE OFENSA AO PRINCÍPIO DA SEPARAÇÃO DOS PODERES. CONSTITUCIONAL. DIREITO À SAÚDE. DEVER. PODER PÚBLICO. RECURSO EXTRAORDINÁRIO A QUE SE NEGA PROVIMENTO. (RE 429903, Relator(a): Min. RICARDO LEWANDOWSKI, Primeira Turma, julgado em 25/06/2014, ACÓRDÃO ELETRÔNICO DJe-156 DIVULG 13-08-2014 PUBLIC 14-08-2014)

${ }^{69}$ PROCESSO CIVIL. ADMINISTRATIVO. INOVAÇÃO RECURSAL DESCABIMENTO. FORNECIMENTO DE MEDICAMENTOS. CRIANÇA. DOENÇA RARA. RISCO DE VIDA. AUSÊNCIA DE REGISTRO NA ANVISA. SITUAÇÃO EXCEPCIONAL DEVIDAMENTE JUSTIFICADA. PERÍCIA MÉDICA DO JUÍZO. POSSIBILIDADE. PRECEDENTES. (AgRg no REsp 1502239/PR, Rel. Ministra DIVA MALERBI (DESEMBARGADORA CONVOCADA TRF $3^{\mathrm{a}}$ REGIÃO), SEGUNDA TURMA, julgado em 18/02/2016, DJe 26/02/2016)

${ }^{70}$ MANDADO DE SEGURANÇA. DOENÇA RARA (FENILCETONURIA). IMPORTAÇÃO DE MEDICAMENTO PELO ESTADO (LOFENALAC). CONCESSÃO DA SEGURANÇA. CONDENAÇÃO EM HONORARIOS. DESCABIMENTO. (REsp 57.608/RS, Rel. Ministro ANTÔNIO DE PÁDUA RIBEIRO, SEGUNDA TURMA, julgado em 16/09/1996, DJ 07/10/1996, p. 37626)

${ }^{71}$ BRASIL. Superior Tribunal de Justiça. Repetitivo sobre remédios não contemplados pelo SUS: juiz deverá analisar pedidos urgentes. 24/05/2017. Notícia referente ao REsp 1657156 Disponível em: $\leq$
} 
A tese estabeleceu que é obrigação do Estado fornecer medicamentos indispensáveis mesmo quando não estejam previstos em atos normativos do SUS, mas para que haja a concessão do pedido é necessário o cumprimento de alguns requisitos cumulativamente. O primeiro é demonstrar, por meio de laudos médicos, a imprescindibilidade ou necessidade do medicamento no tratamento, bem como a prova da ineficácia, para o tratamento devido, dos medicamentos já fornecidos pelo SUS. O segundo é a comprovação da hipossuficiência financeira para arcar com os custos do fármaco pleiteado. Por fim, o medicamente deve ter sido previamente aprovado pela Anvisa, e as exigências estabelecidas só valerão para os processos distribuídos a partir data de conclusão do precedente. ${ }^{72}$

Também, foi identificado na pesquisa "O Papel do Instituto da Repercussão Geral do STF nos Precedentes sobre Direito Sanitário”, que, na análise dos precedentes de repercussão geral no STF sobre questões de direito sanitário, há uma sinalização de maior acolhimento das teses jurídicas sobre a análise do impacto econômico e social das decisões, o que demonstra as considerações sobre considerações de natureza econômica e social são as que mais sensibilizam o STF. ${ }^{73}$

De análise dos precedentes, percebe-se que a questão vem sendo enfrentada pelo Poder Judiciário, mas as questões de natureza econômica estão sempre no arcabouço das decisões, tornando o direito social à saúde atrelado à questão financeira, recaindo da falácia da reserva do possível, fato que cria barreiras para a fruição dos serviços sanitários.

Questiona-se se, diante da explosão de litigiosidade na sociedade brasileira estigmatizada pelas contradições socioeconômicas, será possível que as instâncias judiciais terão "[...] condições de continuar desempenhando com um mínimo de eficácia suas funções tradicionais de absorver as tensões, 'generalizar' o dissenso e reduzir incertezas do sistema político,

http://www.stj.jus.br/sites/STJ/default/pt_BR/ Comunica $\% \quad$ C3\%A7\%C3\%A3o/noticias/Not\%C3\%ADcias/ Repetitivo-sobre-rem\%C3\%A9dios-n\%C3\%A3o-contemplados-pelo-SUS:juiz-dever\%C3\%A1-analisar-pedidos-urgentes>. Acesso em: 12 mar. 2018.

${ }^{72}$ BRASIL. Superior Tribunal de Justiça. Primeira seção define requisitos para fornecimento de remédios fora da lista do SUS. 25/04/2018. Notícia referente ao REsp 1657156 Disponível em: $\leq$ http://www.stj.jus.br/ sites/STJ/default/pt_BR/Comunica\% $\quad$ C3\%A7\% $\quad$ C3\%A3o/ noticias/Not\%C3\%ADcias/Primeira-Se\%C3\%A7\%C3\%A3o-define-requisitos-para-fornecimento-derem\%C3\%A9dios-fora-da-lista-do-SUS >. Acesso em: 12 nov. 2018.

${ }^{73}$ MICHEL, V. et. al. O papel do instituto da repercussão geral do STF nos precedentes sobre direito sanitário. In: STURZA, Ana Elizabeth Cavalcanti; MARTINI, Sandra Regina (org.). A transdisciplinaridade e o Direito: direito à saúde na sociedade em rede. Os movimentos entre os saberes, v. 10. Porto Alegre: Evangraf / Exclamação, 2018. 
limitando e 'desarmando' os conflitos, bem como impedindo a generalização?" 74 .

Boaventura de Sousa Santos analisa que o Poder Judiciário está diante de um dilema, reconhece que o mesmo está apto a resolver todos os problemas que decorrem das assimetrias sociais e econômicas, mas para tanto deve assumir sua quota-parte e politizar-se na solução de conflitos, caso contrário deixara de ter aliados na sociedade e recairá no isolamento. ${ }^{75}$

A discussão sobre o controle judicial das políticas públicas de direito à saúde avançou muito desde a implementação da Constituição Federal de 1988, pois se antes havia dúvidas ou questionamento sobre a sua possibilidade, baseado principalmente na alegação da separação dos Poderes e na teoria da reserva do possível, hoje não há mais dúvidas sobre esta possibilidade. A possibilidade desse procedimento judicial é um alivio para aqueles que padecem de enfermidade diante das falhas e omissões do ente estatal brasileiro.

Por outro lado, é necessário ressaltar que este deveria ser um remédio constitucional para casos específicos e excepcionais, porém no Brasil, por conta exatamente da falha e omissão estatal, a judicialização à saúde está virando uma verdadeira febre, em que se atacam os sintomas da crise e não as causas do descumprimento dos objetivos constitucionais democráticos.

\begin{abstract}
Na medida em que o Poder Judiciário age para suprir a carência da população em ter direitos efetuados, ele assume papel de maior importância no Estado Democrático de Direito, passando a ser mais atuante e a ter uma função política de grande relevância dentro do cenário nacional. Dessa feita, o Judiciário assume um papel ativo, suprimento omissões no caso concreto para implementar o texto constitucional. ${ }^{76}$
\end{abstract}

Conclui-se, então, que o controle judicial das políticas públicas do direito fundamental à saúde é um importante aliado na defesa da população, mas, ao analisar os fenômenos que estão por trás do excesso de judicialização, bem como as consequências, percebe-se que esse não configura um verdadeiro instrumento de mudanças sociais e paradigmas; pelo contrário, este está apenas concedendo uma parcela mínima de direitos para

\footnotetext{
${ }^{74}$ FARIA, José Eduardo. Justiça e conflito. Os juízes em face dos novos movimentos sociais. São Paulo: Editora Revista dos Tribunais, 1991, p. 41.

${ }^{75}$ SANTOS, Boaventura de Souza. Para uma revolução democrática da Justiça. São Paulo: Cortez, 2007.

${ }^{76}$ SILVA; MENDES, op. cit., 2018, p. 87.
} 
aqueles que conseguem ter acesso ao Judiciário e obedecem aos requisitos de processo (de natureza processual e material). Com isso não há a promoção da dignidade humana pelo Estado dito Democrático de Direito, nem mesmo o cumprimento dos objetivos constitucionais.

\section{CONCLUSÃO}

A Constituição Federal de 1988 é um documento normativo primordial na luta pelos direitos fundamentais da população brasileira; contudo, após 30 anos da sua promulgação, o Estado vem falhando no cumprimento dos objetivos constitucionais, principalmente em assegurar a concretização da dignidade humana, na prática. De tal modo, é necessário revisar as garantias fundamentais estabelecidas no texto para diagnosticar como estas estão sendo tratadas e quais as possibilidades de agir diante do descumprimento estatal.

Esta pesquisa teve o intuito de analisar o direito fundamental à saúde, bem como o controle judicial das políticas públicas de direito à saúde, para, sob o enfoque das teorias críticas dos direitos humanos, entender se o mecanismo judicial garante verdadeiro cumprimento dos preceitos constitucionais, com o principal intuito de entender se esse é realmente um mecanismo de promoção do direito à saúde e um instrumento de transformações sociais dos direitos humanos ou se é somente uma forma de resolver conflitos judiciais individuais.

Para tanto, é necessário entender que, constitucionalmente, o direito fundamental à saúde é um direito social, justificado pelo princípio da igualdade, pelo direito à vida e pela dignidade da pessoa humana, só sendo completamente efetivado quando todos podem usufruir e ter acesso ao mesmo; a prestação deste serviço deve ser universal, de forma igualitária e plena. Ademais, o Estado deve garanti-lo mediante políticas, sendo inicialmente os responsáveis para a implementação os poderes Legislativo e Executivo.

Destaca-se, que, seguindo os ensinamentos da teoria crítica dos direitos humanos, que tem como principal teórico Joaquín Herrera Flores, um direito humano só é concreto e efetivo, quando significa, na pratica, o acesso de todos aos bens necessários para uma vida digna de ser vivida, pois, caso o direito seja apenas normatizado, e não efetua mudanças reais na vida das pessoas, será apenas uma falácia que estabelece o direito a ter 
direitos. Nesse sentido, só há verdadeiramente o direito à saúde, quando este garante à população a efetiva fruição do direito à saúde, para uma vida digna, e não garanta apenas vida de sobrevivência, como deseja a ideologia neoliberal.

Infelizmente, o preceito constitucional que determina que o Poder Público efetive o direito à saúde por meio das políticas públicas, o que não vem sendo cumprido de forma a promover a dignidade humana, o que resulta na crise da saúde pública brasileira. Diante do problema surgem inúmeras demandas para que o Poder Judiciário atue e possa fazer valer os objetivos e mandamentos da Constituição Federal.

Assevera-se que a possibilidade desta revisão, no ordenamento interno, por muito tempo, foi assunto controvertido, por sorte já superada. Considera-se que a possibilidade do Poder Judiciário de interferir nas políticas públicas é um importante instrumento para, na omissão ou má prestação do serviço estatal, forçar o cumprimento dos preceitos constitucionais, garantindo, assim, a efetivação do direito fundamental à saúde, e a consequente manutenção do Estado Democrático de Direito.

Essa possibilidade deve ser garantida na prática, mas a observância do excesso da judiciliazação revela ser uma realidade brasileira preocupante, demonstra um diagnóstico da falha democrática e um imaginário jurídico dos direitos humanos em que este só é exercido no âmbito pósviolatório. Assim, gera-a um conforto proposital do Poder Legislativo e Poder Executivo, já que a eles é licito não cumprir todas as demandas sociais, pois a população se conforma em, diante da falha, acionar o Judiciário para pleitear o direito à saúde individualmente. Cria-se, então, uma expectativa de fruição do direito humano à saúde, apenas quando o mesmo é violado, além de um sentimento individualista em um direito que deveria ser social e coletivo.

Ademais, a realidade da maioria da população brasileira é de exclusão e falta de acesso a inúmeros direitos humanos, o direito ao acesso à justiça, então parte da população não terá possibilidade de exercer o direito na seara pós-violatória.

O controle judicial das políticas públicas de direito à saúde foi uma importante conquista democrática e social, isso não há como negar, que ajuda muitos brasileiros no momento em que sofrem os mandos e desmandos dos poderes públicos brasileiros, mas é importante não esquecer o que está por de trás da necessidade do uso excessivo e rotineiro da judiciliazação da saúde, para não cair na armadilha neoliberal de uso demagogo 
dos direitos humanos. Lembra-se também que, no momento, o imaginário da população aceita como regra geral ter que recorrer ao Judiciário para ter acesso à saúde. Isto faz com que o Estado Democrático entra em colapso, já que o Judiciário deveria ser o último recurso, apenas um remédio em casos excepcionais.

Considera-se, então, que o fenômeno do controle judicial das políticas públicas de direito à saúde não sendo um instrumento efetivo para a transformação real na sociedade, com consequente concretização do direito humano, está então sendo utilizado para gestionar conflitos individuais para aqueles que conseguem ter acesso à Justiça, e que, após vencer esta barreira, preenchem todos os requisitos de natureza processual. Ou seja, o Estado Democrático Brasileiro fracassou na prestação de um direito tão básico e essencial para garantir a dignidade humana do brasileiro.

\section{REFERÊNCIAS}

BARCELLOS, Ana Paula de. A eficácia jurídica dos princípios constitucionais: o princípio da dignidade humana da pessoa humana. 2 ed. rev e atual. Rio de Janeiro: Renovar, 2008.

BARRETO, Vicente de Paulo. Reflexões sobre direitos sociais. In: SARLET, Ingo Wolfgang (Org.). Direitos fundamentais sociais. Estudos de direitos constitucional, internacional e comparado. Rio de Janeiro: Renovar, 2003.

BARROSO, Luís Roberto. Curso de Direito Constitucional Contemporâneo: Os Conceitos Fundamentais e a Construção do Novo Modelo. $7^{\circ}$ ed. São Paulo: Saraiva Educação, 2018.

BONETI, Lindomar Wessler. Políticas públicas por dentro. Ijui (RS): Unijui, 2007.

BRASIL. [(1988) Constituição]. Constituição da República Federativa do Brasil, assinada em 05 de outubro de 1988. Brasília: Senado Federal, 1988.

BRASIL. Supremo Tribunal Federal. RE-AgR 271286 RS. Psciente com HIV/AIDS. Pessoa destituída de recursos financeiros. Direito à vida e à saúde. Fornecimento gratuito de medicamentos. Dever constitucional do poder público (Cf. arts. $5^{\circ}$ caput e 196). Relator. Celso de Mello. Órgão Julgador: Segunda Turma. Julgamento: 12 de setembro de 2000. Publicação: Diário de Justiça de 24-11-2000 PP-00101 Ement Vol-02013-07 pp-01409. Brasília, DF, 2000.

BRASIL. Supremo Tribunal Federal. RE 566471 RG / RN - Rio Grande do Norte. Saúde. Assistência. Medicamento de alto custo. Fornecimento. Órgão julgador: Tribunal Pleno. Relator: Min. Marco Aurélio. Repercussão Geral no Recurso Extraordinário. Julgamento: 15/11/2007. Diário de Justiça [eletrônico] de 07/12/2007. Brasília, DF, 2007.

BRASIL. Supremo Tribunal Federal. RE 643435. Recurso Extraordinário. Ação Civil Pública. Obrigação de fazer. Elaboração, pelo município, de plano de gerenciamento integrado de resíduos da 
construção civil. Intervenção do Poder Judiciário. Regular prestação jurisdicional. Artigo 225 da Constituição Federal. Meio ambiente ecologicamente equilibrado. Direito de terceira geração. Preservação e defesa. Encargo irrenunciável ao poder público e à coletividade. Relator: Min. Luiz Fux. Órgão julgador: Tribunal Pleno. Julgado em 18/03/2013.Publicação: Diário de Justiça [eletrônico] n ${ }^{\circ}$ 054, Divulg 20/03/2013 Public 21/03/2013. Brasília, DF, 2013.

BRASIL. [(1998) Constituição]. Emenda Constitucional 95 de 16 de dezembro de 2016 [Novo Regime Fiscal, PEC do Teto dos Gastos Públicos]. Altera o Ato das Disposições Constitucionais Transitórias, para Instituir o Novo Regime Fiscal, e Dá Outras Providências. Diário Oficial da União de 16/12/2016 (p. 2; col. 2). Brasília, DF, 2016.

BRASIL. Superior Tribunal de Justiça. Repetitivo sobre remédios não contemplados pelo SUS: juiz deverá analisar pedidos urgentes. 24/05/2017. Notícia referente ao REsp 1657156 Disponível em: $\leq$ http://www.stj.jus.br/sites/STJ/default/pt BR/ Comunica \% C3\%A7\%C3\%A3o/noticias/Not\%C3\%ADcias/Repetitivo-sobre-rem\%C3\%A9dios-n\%C3\%A3o-contemplados-pelo-SUS:juiz-dever\%C3\%A1-analisar-pedidos-urgentes>. Acesso em: 12 mar. 2018

BRASIL. Superior Tribunal de Justiça. Primeira seção define requisitos para fornecimento de remédios fora da lista do SUS. 25/04/2018. Notícia referente ao REsp 1657156 Disponível em: $\leq$ http://www.stj.jus.br/ sites/STJ/default/pt_BR/Comunica\% C3\%A7\% C3\%A3o/ noticias/Not\%C3\%ADcias/Primeira-Se\%C3\%A7\%C3\%A3o-define-requisitos-para-fornecimento-derem\%C3\%A9dios-fora-da-lista-do-SUS>. Acesso em: 12 nov. 2018.

BREUS, Thiago Lima. Políticas públicas no estado constitucional. Belo Horizonte: Fórum, 2007.

BUCCI, Maria Paula Dallari. "Notas para uma metodologia jurídica de análise de políticas públicas". In: FORTINI, Cristina; ESTEVES, Júlio C. S; DIAS, Maria Teresa F. (Org.) Políticas públicas possibilidades e limites. Belo Horizonte: Fórum. 2008.

CAPELLA, Ana Claudia N. Perspectivas teóricas sobre o Processo de Formulação de Políticas Públicas. In: HOCHMAN, Gilberto; ARRETCHE, Marta; MARQUES, Eduardo (Org). Políticas públicas no Brasil. Rio de Janeiro: Fiocruz, 2007.

DALLARI, Dalmo de Abreu. Elementos de teoria geral do Estado. 24. ed. São Paulo: Saraiva, 2003.

DIAS, Jean Carlos. O Controle judicial das políticas públicas. São Paulo: Método, 2007.

FALLON JR., Richard H. The dynamic constitution. Cambridge: Cambridge University Press, 2004.

FARIA, José Eduardo. Justiça e conflito. Os juízes em face dos novos movimentos sociais. São Paulo: Editora Revista dos Tribunais, 1991.

FIGUEIREDO, Mariana Filchtiner. Direito fundamental à saúde: parâmetro para sua efetividade. Porto Alegre: Livraria do Advogado Editora, 2007.

GINSBURG, Tom. Judicial review in demorcracies. Cambridge: Cambridge University Press, 2003.

GARAPON, Antoine. O juiz e a democracia. O guardião de promessas. 2. ed. Rio de Janeiro: Revan, 1999. 
HERRERA FLORES, Joaquín. O nome do risco. Breve tratado sobre arte e dignidade. Porto Alegre: Movimento; Florianópolis: Bernúncia, 2007.

HERRERA FLORES, Joaquín. La reinvención de los derechos humanos. Sevilla: Atrapasueños, 2008.

LEAL, Rogério Gesta. A efetivação do direito à saúde por uma jurisdição-serafim: limites e possibilidades. A \& C revista de Direito Administrativo e Constitucional, Belo Horizonte, ano 6, n. 25, p.2540, jul/set. 2006; ISSN 1516-3210.

MICHEL, V. et. al. O papel do instituto da repercussão geral do STF nos precedentes sobre direito sanitário. In: STURZA, Ana Elizabeth Cavalcanti; MARTINI, Sandra Regina (org.). A transdisciplinaridade e o Direito: direito à saúde na sociedade em rede. Porto Alegre: Evangraf / Exclamação, 2018, Os movimentos entre os saberes, v. 10.

ORGANIZAÇÃO DAS NAÇÕES UNIDAS (ONU). Declaração Universal dos Direitos Humanos. Adotada e proclamada pela Assembleia Geral das Nações Unidas (resolução 217 A III) em 10 de dezembro 1948. Paris, 1948.

PEC QUE restringe gastos públicos é aprovada e vai a promulgação. 2016. In: Senado Notícias. Disponível em: < https://www12.senado.leg.br/noticias/materias/ 2016/12/13/pec-que-restringe-gastospublicos-e-aprovada-e-vai-a-promulgacao > Acesso em: 22 out. 2018.

ORDACGY, André da Silva. A tutela de saúde como um direito fundamental do cidadão. 24.05.2006. Disponível em: < http://www.ceap-rs.org.br/wp-content/uploads/2014/02/Direito-Humano-a-saude-oublica.pdf >. Acesso em: 23 mar. 2018.

PEC TETO dos gastos: uma perda bilionária para o SUS em 2019. 25 Setembro 2018. In: Instituto Humanitas Unisinos. Disponível em: <http://www.ihu.unisinos.br/78-noticias/583072-pec-teto-dosgastos-uma-perda-bilionaria-para-o-sus-em-2019>. Acesso em: janeiro de 2019.

PIOVESAN, Flávia. Direitos humanos e direito constitucional internacional. 15. ed. São Paulo: Saraiva, 2015.

PIMENTA, José Marcelo Barreto. Reserva do possivel e a força dirigente dos direitos fundamentais sociais. Curitiba: Juruá Editora, 2016.

PISARELLO, Gerard. Los derechos sociales y sus garantías. Madrid: Editorial Trotta, 2007.

PRONER Carol. Teoría, crítica dos direitos humanos: das lutas aos direitos sociais. Rio de Janeiro: Lumen Juris, 49-64, 2011.

RAMOS, André de Carvalho. Curso de direitos humanos. 5. ed. São Paulo: Saraiva, 2018.

RUBIO, David Sánchez. Encantos e desencantos dos direitos humanos: De Emancipações, libertações e Dominações. Porto Alegre: Livro do Advogado, 2014.

SANTOS, Boaventura de Souza (org). A globalização e as ciências sociais. São Paulo: Cortez, 2005. 
SANTOS, Boaventura de Souza. Para uma revolução democrática da Justiça. São Paulo: Cortez, 2007.

SANTOS, Boaventura de Souza. Direitos Humanos, Democracia e Desenvolvimento. In: SANTOS, Boaventura de Souza; CHAI, Marilena. Direitos humanos, democracia e desenvolvimento. São Paulo: Cortez, 2013; p 41-133.

SILVA, José Afonso da. Curso de direito constitucional positivo. 18. ed. São Paulo: Revista dos Tribunais, 2000.

SILVA, Luciana Aboim Machado Gonçalves da; MENDES, Ana Carolina Fontes Figueiredo. Controle judicial das políticas públicas e o direito fundamental à saúde no sistema jurídico brasileiro. In: STURZA, Ana Elizabeth Cavalcanti; MARTINI, Sandra Regina (org.). A transdisciplinaridade e o Direito: direito à saúde na sociedade em rede. Os movimentos entre os saberes, v. 10. Porto Alegre: Evangraf / Exclamação, 2018.

STRECK, Lenio Luiz. O ativismo judicial existe ou é imaginação de alguns? Senso Incomum Conjur. 13 de jun 2013. Disponível em: < https://www.conjur.com.br/2013-jun-13/senso-incomum-ativismoexiste-ou-imaginacao-alguns > Acesso em: 22 out. 2018

VIEIRA, Oscar Vilhena. Direitos fundamentais: uma leitura da jurisprudência do STF. 2. ed. São Paulo: Malheiros, 2017.

WALLERSTEIN, Immanuel. O universalismo europeu. A retórica do poder. São Paulo: Boitempo, 2007. 